\title{
THE SEROPREVALENCE OF THE HEPATITIS B VIRUS IN ITALIAN MEDICAL STUDENTS AFTER 3 DECADES SINCE THE INTRODUCTION OF UNIVERSAL VACCINATION
}

\section{PIETRO SARTORELLI ${ }^{1}$, FEDERICO OCCHIALINI ${ }^{2}$, ROSALIA MICELI ${ }^{3}$, ANTONELLA PIETRONIGRO ${ }^{3}$, LAURA BIANCIARDI ${ }^{2}$, CHIARA SALINI ${ }^{4}$, and GABRIELE MESSINA ${ }^{5}$}

University of Siena, Siena, Italy

${ }^{1}$ Department of Medical Biotechnology, Unit of Occupational Health Azienda Ospedaliera Universitaria Senese

${ }^{2}$ Department of Medical Biotechnology

${ }^{3}$ Postgraduate School of Occupational Medicine

${ }^{4}$ Postgraduate School of Public Health

${ }^{5}$ Department of Molecular and Developmental Medicine

\begin{abstract}
Objectives: Since 1991 hepatitis B vaccination has been mandatory for all newborns in Italy. The aim of the study was to verify the long-term seroprevalence and the efficacy of hepatitis B vaccination in medical students of the University of Siena. Material and Methods: A cross-sectional observational study was conducted on a population of 850 medical students of the University of Siena (322 males and 528 females, mean age: 23 years) by obtaining from the medical reports the serological analysis data for the total anti-hepatitis B antibodies (HBsAb) and information on hepatitis B vaccination (number of vaccine doses, age at the first vaccination, time since the final vaccination dose, country of origin). Raw odds ratios (ORs) and 95\% confidence intervals (CIs) were initially calculated to evaluate the association between 2 variables. The adjusted ORs were then calculated using a multivariate logistic regression model to study the association between the variables and the possible confounding factors. Results: Overall, 593 students (69.76\%) were immunized against hepatitis B, while 257 (30.24\%) had HBsAb antibody titer $<10 \mathrm{mIU} / \mathrm{ml}$. From the OR calculation, an inverse correlation emerged between seropositivity to hepatitis B and age, and between seropositivity to hepatitis B and the age at the first vaccination dose. There was also a correlation between seropositivity and the number of vaccination doses received. By performing the multivariate logistic analysis, correlations with these variables were confirmed. Conclusions: A significant part of the studied population was not immunized against hepatitis B virus, despite the fact that vaccination had been carried out as prescribed by law. The results of the study reaffirm the importance of health surveillance in subjects at biological risk such as medical students. Int J Occup Med Environ Health. 2022;35(1):75-80
\end{abstract}

Key words:

hepatitis B, vaccination, medical students, immunization, hepatitis B antibodies, seroepidemiological studies

Received: February 16, 2021. Accepted: May 19, 2021.

Corresponding author: Pietro Sartorelli, University of Siena, Department of Medical Biotechnology, Unit of Occupational Health Azienda Ospedaliera Universitaria Senese, Viale Bracci 16, 53100 Siena, Italy (e-mail: pietro.sartorelli@unisi.it). 


\section{INTRODUCTION}

Hepatitis B represents a worldwide public health concern. Vaccination is an effective form of infection prevention $[1,2]$; therefore, many countries have established extensive vaccination programs [3]. Since 1991 hepatitis B vaccination has been mandatory in Italy for all newborns with a scheme that provides the administration of 3 doses at the third, fifth, and 11th month of life. In order to be considered immunized against the hepatitis B virus, a person is required to have the minimum serological antibody concentration of $\geq 10 \mathrm{mIU} / \mathrm{ml}$ - a target that is usually reached after having administered the 3 compulsory boosters. In some individuals, the antibody response may become less effective over time.

For this reason, a periodic evaluation of the total antihepatitis B antibodies (HBsAb) is recommended in subjects exposed to jobs at risk (such as healthcare workers), as well as consulting the occupational physician in order to establish suitability for the job. At the University of Siena, medical students who, among other things, access the hospital to carry out training internships, are checked to verify if they are immune to hepatitis B by means of $\mathrm{HBsAb}$, and the subjects who prove to be seronegative are then given the vaccination according to the criteria described above.

The study aimed to verify the long-term seroprevalence and the efficacy of hepatitis B vaccination in students enrolled in degree courses in medicine and surgery, dentistry and other medical professions at the University of Siena.

\section{MATERIAL AND METHODS}

\section{Subjects and settings}

Among a total population of 1107 students enrolled in the degree courses in medicine and surgery, dentistry and other health professions at the University of Siena, who were given a preventive examination in March 2018March 2020 before the start of their internship, 850 subjects were selected (322 males and 528 females, mean age: 23 years, range: $18-72$ years, 811 Italians and 39 foreigners). The exclusion criteria in the population selection were as follows:

- a lack of a vaccination booklet,

- a lack of any serological tests,

- hepatitis B vaccination not carried out,

- students with chronic hepatitis B.

A cross-sectional observational study was conducted. By reviewing the medical records compiled in the health surveillance program of the participants in these degree courses, the following data were obtained:

- a serological analysis report for HBsAb and hepatitis B surface antigen (HBsAg),

- the number of doses of the hepatitis B vaccine received by each student $(1,2, \geq 3)$,

- age at which the first vaccination dose was administrated (in or after the first year of age),

- elapsed time since the final vaccination dose ( $>20$ years or $<20$ years),

- where the students come from (born in Italy or abroad). The HBsAb titer was detected using the immunofluorescence technique (CMIA, Abbott Laboratories, Abbott Park, U.S). The serological reference values of the total $\mathrm{HBsAb}$ were the international values used by the WHO standard criteria. For the purposes of the study, students with $\mathrm{HBsAb} \geq 10 \mathrm{mIU} / \mathrm{ml}$ were considered protected against hepatitis $\mathrm{B}$, a value also considered in other Italian and international studies [4-8].

\section{Statistical analysis}

A minimum sample size of 839 was estimated considering a prevalence of immunized persons at $30 \%$, as reported by Dini et al. [6], with the first type error of 0.05 and precision of about 0.03 .

Preliminary descriptive analysis was carried out, and qualitative variables were summarized with absolute frequencies and percentages, the quantitative ones being denoted as mean $(\mathrm{M}) \pm$ standard deviation $(\mathrm{SD})$. 
The association between the variables was carried out using the $\chi^{2}$ test and the $\mathrm{t}$-test to evaluate the age difference between the 2 groups.

Crude odds ratios (ORs) and their 95\% confidence intervals (CIs) were estimated. The adjusted ORs were then estimated using a multivariate logistic regression model and performing a stepwise procedure. The model was firstly constituted by significant variables at the univariate analysis. The $\mathrm{p}$-value of $<0.05$ was considered statistically significant. The statistical analysis was carried out using STATA SE/16.0 (StataCorp LLC, Texas, USA).

\section{RESULTS}

Based on analyzing the serological results, 593 students (69.76\%) were immunized against hepatitis B, while 257 (30.24\%) had HBsAb $<10 \mathrm{mIU} / \mathrm{ml}$.

Table 1 shows the characteristics of the population of 850 students working in the health service sector divided by gender, nationality, the number of hepatitis $B$ vaccination doses received, the age at which the first vaccination dose was administrated, and the elapsed time since the last vaccination.

From the OR calculation, an inverse correlation emerged between seropositivity to hepatitis $B$ and age, and between seropositivity to hepatitis B and the age at which the first vaccination dose was administered. This means that the younger the subject, the greater the probability of immunity to hepatitis B (OR $=0.92,95 \% \mathrm{CI}$ : $0.88-0.95)$, while those who received the first vaccination dose within a year after birth were less likely to be immune to hepatitis B (OR $=0.31,95 \%$ CI: 0.16-0.60). There was also a correlation between seropositivity and the number of vaccination doses carried out, with a lower probability of immunization when the doses decreased $(\mathrm{OR}=0.53,95 \% \mathrm{CI}: 0.32-0.88)$. By performing the multivariate logistic analysis, correlations with these variables were confirmed according to age $(\mathrm{OR}=0.92,95 \% \mathrm{CI}$ : $0.85-0.98)$; with the age at the first dose $(\mathrm{OR}=0.42$,
95\% CI: 0.20-0.86); with the number of doses performed $(\mathrm{OR}=0.45,95 \% \mathrm{CI}: 0.24-0.84)$. The calculation of the raw ORs showed no significant association between hepatitis B seropositivity and nationality (Italian or foreign), gender or if the last dose was given $>20$ years or $<20$ years before. Table 2 summarizes the values of the main variables in the subjects immunized and non-immunized to HBV, and the relative $\mathrm{p}$-value obtained from the $\mathrm{OR}$ calculation.

\section{DISCUSSION}

Transmission of the hepatitis B virus within the healthcare setting is universally recognized as an important source of new infections. This is largely due to the exposure of healthcare workers and medical students (such as the studied population) to potentially infected materials and objects such as needles and scalpels.

In Italy, the hepatitis B vaccine has been compulsory since 1991. However, any booster dose for health professionals who are no longer immunized are not mandatory, even though strongly recommended.

The results have shown that $>30 \%$ of the students were not immunized against the hepatitis B virus and, therefore, were at risk of contracting the infection. This percentage is similar to that observed by Dini et al. [6] in the students who attended the University Hospital San Martino in Genoa, but higher than those reported in other Italian studies $[7,9,10]$. In other Italian hospitals, seronegative students made up about $38 \%$ of the total $[8,11]$. Errors in administering the number of doses required (12 students took $<3$ doses) or in administering the doses (the site and method of administration) may be a possible explanation for the reduced vaccination coverage in some subjects.

In the studied population, the students who received the vaccine within the first year of age were less effectively covered, compared to those who received it later, confirming the results of another study [8], while being in contrast to the WHO recommendations that stress 
Table 1. Characteristics of a population of 850 medical students who were given a preventive examination at the University of Siena in March 2018-March 2020, divided into immunized and non-immunized students

\begin{tabular}{|c|c|c|c|}
\hline \multirow{3}{*}{ Variable } & \multicolumn{3}{|c|}{$\begin{array}{l}\text { Participants } \\
(\mathrm{N}=850)\end{array}$} \\
\hline & \multirow[b]{2}{*}{ total } & \multicolumn{2}{|c|}{ antibodies concentration } \\
\hline & & $\begin{array}{c}<10 \mathrm{mlU} / \mathrm{ml} \\
(\mathrm{N}=257,30.24 \%)\end{array}$ & $\begin{array}{c}>10 \mathrm{mlU} / \mathrm{ml} \\
(\mathrm{N}=593,69.76 \%)\end{array}$ \\
\hline \multicolumn{4}{|l|}{ Age [years] } \\
\hline$M \pm S D$ & $24 \pm 3.34$ & $23 \pm 2.47$ & $24 \pm 3.61$ \\
\hline $\min .-\max$ & $18-72$ & $18-46$ & $18-72$ \\
\hline \multicolumn{4}{|l|}{ Gender [n (\%)] } \\
\hline males & $322(37.88)$ & $94(29.19)$ & $228(70.81)$ \\
\hline females & $528(62.12)$ & $163(30.87)$ & $365(69.13)$ \\
\hline \multicolumn{4}{|l|}{ Nationality [n (\%)] } \\
\hline Italian & 811 (95.41) & $247(30.46)$ & $564(69.54)$ \\
\hline foreign & $39(4.59)$ & $10(25.64)$ & $29(74.36)$ \\
\hline \multicolumn{4}{|l|}{ Age at the first vaccination dose [n (\%)] } \\
\hline first year of age & $765(90)$ & $246(32.16)$ & $519(67.84)$ \\
\hline after the first year & $85(10)$ & $11(12.94)$ & $74(87.06)$ \\
\hline \multicolumn{4}{|c|}{ Elapsed time since the last vaccination [n (\%)] } \\
\hline$<20$ years & $207(24.35)$ & $62(29.95)$ & $145(70.05)$ \\
\hline$>20$ years & $643(75.65)$ & $195(30.33)$ & $448(69.67)$ \\
\hline \multicolumn{4}{|c|}{ Hepatitis B vaccination doses administrated [n (\%)] } \\
\hline 1 & $3(0.35)$ & $2(66.67)$ & $1(33.33)$ \\
\hline 2 & $9(1.06)$ & $4(44.44)$ & $5(55.56)$ \\
\hline 3 & $799(94)$ & $244(30.54)$ & $555(69.46)$ \\
\hline 4 & $35(4.12)$ & $7(20)$ & $28(80)$ \\
\hline 5 & $4(0.47)$ & $0(0)$ & $4(100)$ \\
\hline
\end{tabular}

the importance of vaccinating infants at birth to prevent perinatal transmission [2]. One possible explanation may be the lesser interaction between $\mathrm{T}$ and $\mathrm{B}$ lymphocytes in the infant rather than in the more mature child. There may also be an individual variability in the immune response to vaccination with consequent variability in the post-vaccination immunity.

The correlation between the immunization status and the number of doses administrated confirms the usefulness of booster doses of the vaccine in uncovered subjects, in order to increase the total vaccination coverage [12-14]. In this regard, in an Italian population of students in the health sector, an anamnestic response was observed in $>95 \%$ of the subjects who had received the booster dose because they were not immunized [6].

In the studied population, there were no relevant differences between the students who had been vaccinated $>20$ years before and those vaccinated $<20$ years before, while another study found a significant decline 
Table 2. Effect of crude and adjusted variables on the students immunized and non-immunized to hepatitis B at the University of Siena in March $2018-$ March 2020

\begin{tabular}{|c|c|c|c|c|}
\hline Variable & OR crude $(95 \% \mathrm{Cl})$ & $\mathrm{p}$ & OR adjusted (95\% Cl) & $\mathrm{p}$ \\
\hline Age (from the youngest) & $0.92(0.88-0.95)$ & 0.0001 & $0.92(0.85-0.98)$ & 0.014 \\
\hline Gender (males vs. females) & $0.92(0.88-0.96)$ & 0.6054 & - & - \\
\hline Nationality (foreign vs. Italian) & $0.79(0.38-1.64)$ & 0.5227 & - & - \\
\hline $\begin{array}{l}\text { Age at the first vaccination dose } \\
\text { (after vs. before the first year) }\end{array}$ & $0.31(0.16-0.60)$ & 0.0003 & $0.42(0.20-0.86)$ & 0.019 \\
\hline $\begin{array}{l}\text { Elapsed time since the last vaccination } \\
\qquad(>20 \text { years vs. }<20 \text { years) }\end{array}$ & $1.02(0.72-1.43)$ & 0.9187 & - & - \\
\hline $\begin{array}{l}\text { Number of hepatitis B vaccination doses administrated } \\
\text { (1-5 doses) }\end{array}$ & $0.53(0.32-0.88)$ & 0.0146 & $0.45(0.24-0.84)$ & 0.012 \\
\hline
\end{tabular}

in the antibody titers as the duration of post-vaccination increased [15]. There was also no substantial difference in the level of immunization between female and male subjects, and between Italian students compared to those of other nationalities.

\section{CONCLUSIONS}

A significant part of the studied population was not immunized against the hepatitis B virus although the vaccination had been administered as prescribed by law. This should be taken into account at the beginning of curricular internship in hospital wards, since many students are at risk of developing the hepatitis infection as a result of contact with infected blood, contaminated needles and scalpels or other infected material.

The results of the study reaffirm the importance of health surveillance in subjects at biological risk such as medical students. In this context, occupational physicians should improve the vaccination rates by limiting the number of non-immunized subjects in their professional group, in order to increase the actual safety of healthcare workers, in particular medical students.

\section{ACKNOWLEDGMENTS}

The authors would like to thank Prof. Maria Grazia Cusi (Department of Medical Biotechnology, University of Siena, Siena,
Italy) and Dr. Riccardo Romeo (Unit of Occupational Medicine, Azienda Ospedaliera Universitaria Senese, University of Siena, Siena, Italy) for their kind collaboration.

\section{REFERENCES}

1. Ng KP, Ngeow YF. Hepatitis B sieroprevalence among University of Malaya Students in the Post-universal Infant Vaccination Era. Med J Malaysia. 2013;68(2):144-7.

2. WHO. Hepatitis B vaccines: WHO position paper, July $2017-$ Recommendations. Vaccine. 2019;37(2):223-5, https://doi. org/10.1016/j.vaccine.2017.07.046.

3. Haverkate M, D’Ancona F, Giambi C, Johansen K, Lopalco PL, Cozza V, et al. Mandatory and recommended vaccination in the EU, Iceland and Norway: results of the VENICE 2010 survey on the ways of implementing national vaccination programmes. Euro Surveill. 2012;17(22):20183, https://doi. org/10.2807/ese.17.22.20183-en.

4. Bini C, Grazzini M, Chellini M, Mucci N, Arcangeli G, Tiscione E, et al. Is hepatitis $\mathrm{B}$ vaccination performed at infant and adolescent age able to provide long-term immunological memory? An observational study on healthcare students and workers in Florence, Italy. Hum Vaccin Immunother. 2018;14(2):450-5.

5. Bruce MG, Bruden D, Hurlburt D, Zanis C, Thompson G, Rea L, et al. Antibody levels and protection after hepatitis B vaccine: results of a 30-year follow-up study and response to 
a booster dose. J Infect Dis. 2016;214(1):16-22, https://doi. org/10.1093/infdis/jiv748.

6. Dini G, Toletone A, Barberis I, Debarbieri N, Massa E, Paganino $\mathrm{C}$, et al. Persistence of protective anti-HBs antibody levels and anamnestic response to HBV booster vaccination: A cross-sectional study among healthcare students 20 years following the universal immunization campaign in Italy. Hum Vaccin Immunother. 2017;13(2):440-4, https:/doi. org/10.1080/21645515.2017.1264788.

7. Lamberti M, De Rosa A, Garzillo EM, Corvino AR, Sannolo N, De Pascalis S, et al. Vaccination against hepatitis b virus: are Italian medical students sufficiently protected after the public vaccination programme? J Occup Med Toxicol. 2015;10:41, https://doi.org/10.1186/s12995-015-0083-4.

8. Verso MG, Lo Cascio N, Noto Laddeca E, Amodio E, Stellino S, Currieri M, et al. Predictors of Hepatitis B Surface Antigen Titers two decades after vaccination in a cohort of students and post-graduates of the Medical School at the University of Palermo, Italy. Ann Agric Environ Med. 2017:24(2):303-6, https://doi.org/10.26444/aaem/74716.

9. Coppeta L, Pompei A, Balbi O, De Zordo LM, Mormone F, Policardo S, et al. Persistence of Immunity for Hepatitis B Virus among Heathcare Workers and Italian Medical Students 20 Years after Vaccination. Int J Environ Res Public Health. 2019;16(9):1515, https://doi.org/10.3390/ijerph16091515.

10. Trevisan A. Long-term persistence of immunity after hepatitis B vaccination: A fact, not a fancy. Hum Vaccin
Immunother. 2017;13(4):916-7, https://doi.org/10.1080/21 645515.2016.1257451.

11. Bianchi FP, Gallone MS, Gallone MF, Larocca AMV, Vimercati L, Quarto M, et al. HBV seroprevalence after 25 years of universal mass vaccination and management of nonresponders to the anti-Hepatitis B vaccine: an Italian study among medical students. J Viral Hepat. 2019;26(1):136-44, https://doi.org/10.1111/jvh.13001.

12. Bagheri-Jamebozorgi M, Keshavarz J, Nemati M, Mohammadi-Hossainabad S, Rezayati MT, Nejad-Ghaderi M, et al. The persistence of anti-HBs antibody and anamnestic response 20 years after primary vaccination with recombinant hepatitis B vaccine at infancy. Hum Vaccin Immunother. 2014;10(12):3731-6.

13. Mahallawi W. Persistence of hepatitis B surface antibody and immune memory to hepatitis B vaccine among medical college students in Madinah. Ann Saudi Med. 2018;38(6):4139, https://doi.org/10.5144/0256-4947.2018.413.

14. Nagashima S, Yamamoto C, Ko K, Chuon C, Sugiyama A, Ohisa $\mathrm{M}$, et al. Acquisition rate of antibody to hepatitis B surface antigen among medical and dental students in Japan after three-dose hepatitis B vaccination. Vaccine. 2018;37(1):14551, https://doi.org/10.1016/j.vaccine.2018.11.019.

15. Sahana HV, Sarala N, Prasad SR. Decrease in Anti-HBs Antibodies over Time in Medical Students and Healthcare Workers after Hepatitis B Vaccination. Biomed Res Int. 2017;2017:1327492, https://doi.org/10.1155/2017/1327492.

This work is available in Open Access model and licensed under a Creative Commons Attribution-NonCommercial 3.0 Poland License - http://creativecommons.org/ licenses/by-nc/3.0/pl/deed.en. 